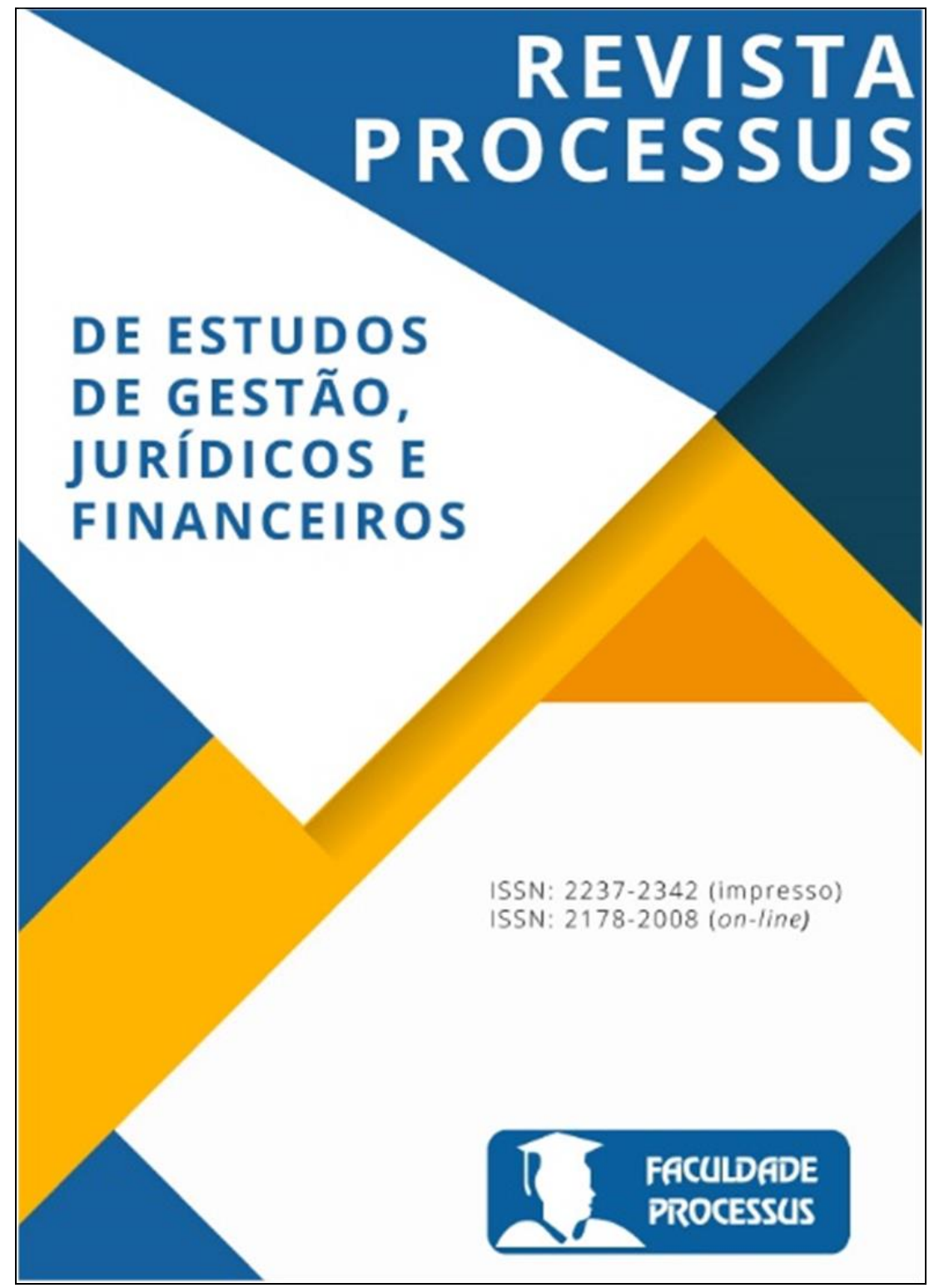

Revista Processus de Estudos de Gestão, Jurídicos e Financeiros

ISSN: 2237-2342 (impresso)

L-ISSN: 2178-2008 (on-line)

Ano VI, Vol.VI, n.21, jan./mar., 2015.

Tramitação editorial:

Data de submissão: 30/01/2015.

Data de reformulação: 15/02/2015.

Data de aceite definitivo: 28/02/2015.

Data de publicação: 20/03/2015. 


\title{
CONTROLE DE JURIDICIDADE - UMA ANÁLISE À LUZ DO INTERESSE PÚBLICO
}

\author{
Bruno Augusto Prenholato ${ }^{1}$
}

RESUMO: O artigo em questão visa a apresentar estudo relativo ao interesse público e sua manifestação junto às decisões judiciais, forma de controle e exame da juridicidade das normas que podem ser extraídas das decisões judiciais. Neste estudo, propõem-se ainda a elaboração de mecanismo de controle, tendo como fundamento principal o interesse público e a consequencialidade dos entendimentos firmados pelas cortes de justiça de nosso país.

PALAVRAS-CHAVE: Interesse público. Decisão judicial. Juridicidade.Controle.

ABSTRACT: The article in question is about to present the study on the public interest and its manifestation with the judicial decisions, how to control and the examination of the legality of rules that can be drawn of judgments. In this study, still propose up the development control mechanism, aiming the public interest and the consequentiality of understanding signed by the courts of our country.

KEYWORDS: Public interests. Judicial decisions.LegalityControl.

\section{Introdução:}

O ativismo judicial, como forma de controle e equilíbrio das relações institucionais dos diversos poderes do Estado tem atingido, nos últimos tempos, altíssimo grau de atuação, conforme se tem observado das diversas decisões judiciais prolatadas na mais alta corte de justiça do país. O Supremo Tribunal Federal, cuja formação é também o retrato político de um poder, embora não legitimado diretamente pela vontade popular, tem decidido questões de interesse público que afloram junto àquele alto sodalício, com intensas repercussões sociais, na medida em que, através de instrumentos de natureza processual,

\footnotetext{
${ }^{1}$ Graduado em DIREITO pela Universidade Católica de Brasília (2002). Atualmente é professor universitário do Instituto Processus, atuando, principalmente, nos seguintes temas: direito público, direito tributário e cooperativismo. Em 2008 defendeu sua dissertação de mestrado pela Universidade Católica de Brasília, obtendo o título de mestre em Direito. É advogado militante na área de direito empresarial, constitucional e outras. Hodiernamente é professor das disciplinas de Empresarial I, Direito Civil (Contratos) e Direito Previdenciário.
} 
como é o caso da repercussão geral, afetam as mais diversas e variadas relações jurídicas sociais existentes, ora concretizando o interesse público em geral, ora celebrando o interesse do Estado ou da Administração.

Neste cenário de franco avanço das relações sociais, o Supremo Tribunal Federal, a exemplo de outros tribunais igualmente importantes, atuam, certamente, consertados no interesse de se promover a justiça ao cidadão comum, todavia, a visão ontológica do conceito de justiça, amplificado de forma gradual e muitas vezes exageradamente legalista, conduzem o jurisdicionado a um processo de subalternalização de certas questões, a controles estatais que afastam a justa apreciação do Poder Judiciário, como deveria acontecer.

Recentemente, no julgamento do RE 631240, de relatoria do Ministro Luís Roberto Barroso, o STF assentou o entendimento de que o segurado vinculado ao INSS, ao provocar discussão judicial acerca de benefício prestacional do sistema de seguridade, deveria, inicialmente, requerer pedido administrativo, tornando-se tal exigência verdadeira condição da ação.

Num passado não tão distante, a questão da imposição da obrigatoriedade de o jurisdicionado submeter eventual litígio a um órgão estranho ao Poder Judiciário, como forma de se estabelecer um procedimento preliminar, antes do acesso ao judiciário, não é novidade. No caso da justiça laboral, é de conhecimento geral o art. 625-D da CLT, o qual propugnava ao trabalhador a obrigatoriedade de submeter a lide a uma comissão prévia de conciliação, como forma de introduzir à relação jurídica tratada a conciliação, negociação e mediação, a fim de se obter a solução das lides, antes mesmo do acesso ao judiciário.

Tal proposta, embora bem intencionada, já que a ideia central de tal imposição seria a de desafogar a justiça do trabalho do crescente e infindável número de demandas, acabou por criar um procedimento preliminar de poucos resultados. Ao contrário, tais comissões tiveram o insucesso de criar verdadeira polarização entre os litigantes, que preferiam resolver seus problemas com a intervenção de um juiz verdadeiramente investido em jurisdição. Para as comissões de conciliação prévia, faltava ainda a confiança e a credibilidade do procedimento, que, infelizmente, não foram conquistados adequadamente. Por fim, as comissões se transformaram em palco de disputas sindicais e patronais, que em nada auxiliavam a solução dos conflitos.

Como era de se esperar, o próprio Supremo se viu obrigado a examinar tais questões a partir da ADI 2160 e 2139, as quais suspenderam a obrigatoriedade das ditas comissões. 
De certo, o que se propõem como estudo para este ensaio é o exame do interesse público que certos posicionamentos judiciais representam para a coletividade, já que no modelo jurídico atual inexistem formas efetivas e eficazes de se promover o controle do interesse público ou o grau de afetação deste instrumento junto à sociedade.

Por certo, os instrumentos de controle servem ao Estado e à sociedade como um todo, pois devem funcionar legitimados pelo interesse coletivo, sempre buscando a conformação da vontade que traga viabilidade social, econômicae jurídica, sem nos esquecermos da necessária preservação do Estado. Portanto, o sistema de controles não deve estar a serviço exclusivo de um poder de fato, mas, submete-se a um poder de direito. Muitas vezes, quando a decisão tomada no âmbito administrativo ou judicial se traduzem em um distanciamento entre o poder de fato e o poder de direito, temos verdadeira subversão da ordem democrática, o que não se pode tolerar.

Neste momento os mecanismos de controle devem atuar eficazmente, afastando do sistema jurídico a anomalia causadora da violação ao interesse público e coletivo.

Certamente, a criação de novos modelos de controle se revela um tanto quanto polêmica. Todavia, em um modelo democrático complexo como é o sistema legal brasileiro, a diluição do poder representa inegável contribuição e fortalecimento do modelo democrático, na medida em que se estará oportunizando a diversos setores da sociedade a participação na construção de um modelo de democracia justa, solidária e fraterna.

Mas, para que tal modelo não ressoe vazio e nada pragmático, de que forma podemos reforçar o interesse público junto das decisões judiciais e administrativas, reduzindose o interesse exclusivo de alguns setores da sociedade?

Pois bem, a resposta para tal questionamento é de fundamento plúrimo. Em primeiro lugar, as bases de qualquer sistema de controle devem estar alicerçadas junto daquele órgão, que, inevitavelmente, deve sofrer o processo de confrontação, fiscalização e controle, através do reforço de princípios fundamentais de inspiração constitucional. O controle realizado pelo próprio órgão prolator da decisão é fundamental, pois, a submissão de qualquer decisão ao crivo do interesse público estimula a criação de estado de consciência daquele que possui o ônus decisório.

Além disso, o controle interno, que é realizado com exclusividade por quem deve decidir, alça o interesse publico a uma espécie de comprometimento de todos os órgãos que possuem parcela decisória de poder, aos ideais democráticos de um país. O reforço do ideal democrático, muitas vezes não é estimulado apenas por sistemas complexos de controle, 
ao contrário, admite-se a obtenção de resultados a partir da disposição de sistemas internos de controle.

O interesse público, embora seja considerada uma expressão jurídica de conteúdo variado, traz em sua filologia um núcleo suficiente a criação de um modelo jurídico calcado na realização da vontade não apenas do somatório de todas as vontades privadas, ao contrário, de uma vontade coletiva que represente o todo, o interesse e a manutenção de uma sociedade capilarizada em diversos setores.

Assim, iniciamos nossos estudos acerca do interesse público, suas definições e formas de constatação de seu atingimento, com a finalidade de examinarmos a possibilidade de tal critério - interesse público - como princípio legitimador da força normativa das decisões judiciais ou mesmo administrativas.

\section{O interesse público e sua definição}

Não restam dúvidas de que o interesse público representa uma grande preocupação social, jurídica e administrativa, quando se analisa a atuação de órgãos do Estado em seu atuar.

Certamente, a definição de interesse público não surge de forma natural e evidente, sem que, para alcançarmos seu conteúdo tenhamos de empreender algum esforço ${ }^{2}$. De fato, como afirma Bandeira de Mello, ao se pensa em interesse coletivo, habitualmente, poderíamos imaginar a contraposição de interesses públicos (coletivos) a interesses particulares. De fato, a conceituação da expressão interesse público passa por tal raciocínio, mas dizer apenas isso é dizer muito pouco a respeito do significado da expressão interesse público.

De fato, a expressão em comento tão pouco significa o somatório de todas as vontades particulares, pois, em certa medida, admite-s que o interesse público venha a contrariar um ou outro interesse privado. Mas reduzir a expressão de interesse público ao somatório de vontades é negar a amplitude conceitual e jurídica que é deveras ampla em sua generalidade. Tão pouco podemos compreender o interesse público como sendo algo destoante do interesse de todas as partes, afinal de contas se todas as vontades perfazem uma unanimidade, não faria nenhum sentido calcar o interesse público em algo que caminhe na contramão da vontade ou interesse da imensa maioria.

\footnotetext{
${ }^{2}$ BANDEIRA DE MELlO, Celso Antônio. Curso de Direito Administrativo. São Paulo: Editora Malheiros, 2013, 30 adição. Pp. 53-55.
} 
O interesse coletivo deve, portanto, significar a expressão em que há a predominância do interesse social geral, considerada em seu todo ${ }^{3}$.

Em uma democracia os órgãos ou fontes de poder ${ }^{4}$ ao produzirem leis ou decisões judiciais ou administrativas, invariavelmente de deparam com a confrontação de interesses próprios da Administração, com os interesses particulares. Todavia, aos poderes instituídos convém definir, em dados momentos, especialmente os decisórios, o que é o interesse coletivo.

Sem embargo, sempre que tal definição ultrapassa os limites do todo, ou do interesse coletivo, estaremos diante de uma violação ao interesse público. Na esteia desse raciocínio, teremos um ato anulável, pois a presunção de validade cederia espaço a um vício de ordem material ou formal que contrariariam o interesse coletivo, o interesse público.

Conceitualmente, Bandeira de Mello prefere conceituar o interesse público como sendo o interesse do todo, do conjunto social, catalisado pela dimensão pública dos interesses individuais, ou seja, dos interesses de cada indivíduo enquanto parte da sociedade, considerada juridicamente no Estado.

Tal conceito, em certa medida minimiza grandes problemas oriundos do processo de representação popular, pois, inexiste em nosso modelo jurídico, fórmula adequada à integração política de todas as massas, inclusive os vários setores sociais ${ }^{5}$. Como consequência disso, apontamos o absoluto descrédito com o que o Poder Legislativo conta hoje. Incapazes de representar adequadamente os interesses daqueles que os elegeram, o Legislativo vivencia hoje verdadeira crise representativa.

Inúmeros projetos de lei, verdadeiros natimortos de representatividade, surgem sem qualquer vinculação ao interesse público, pois, ao contrário, estariam voltados à defesa de interesses dos mais poderosos ou de certos grupos hegemônicos. A este respeito, entendemos que a crise representativa que vivenciamos nos dias de hoje relaciona-se diretamente com o modelo de poder empregado em nosso país. Precisamente no século XVIII surgiu uma teoria bastante interessante para tratar do interesse público, ou pelo menos limitar o seu funcionamento. No caso, defendia-se a ideia de que a liberdade como valor supremo conduziria a situações esdrúxulas, onde, de um lado, existiriam indivíduos marginalizados, enquanto, de outro, teríamos cidadãos vivenciando uma série de privilégios, muitas vezes não merecidos.

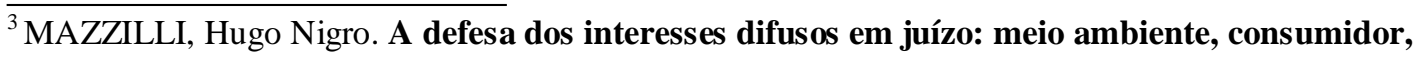
patrimônio cultural, patrimônio público e outros interesses. São Paulo. Editora Saraiva, 2007. P.45. ${ }^{4}$ Entenda-se nesta expressão as fontes de direito como sendo a oigem de onde emanam as fontes de poder, nesta conceituação entendida como: o Poder Executivo, Legislativo e o Poder Judiciário.

${ }^{5}$ DALLARI, Dalmo de Abreu. Elementos de teoria geral do Estado. São Paulo: Saraiva, 2007. P. 306
} 
A solução para tais distorções seria justamente a limitação das liberdades, através de um modelo cujas escolhas do que viria a ser interesse publico seriam fatalmente determinadas pelo Estado. Pura fantasia! O destino de um povo ou Estado jamais podem ser conduzidos de forma livre por um grupo de indivíduos que se investem de sabedoria e capacidades divinas para definir os melhores rumos. Tais opções, como sói acontecer, devem ser determinados pela vontade do todo, no interesse do todo coletivo.

O grande problema de se definir com precisão o que vem a ser o interesse público esbarra na necessidade de examinarmos o próprio modelo jurídico hoje aqui instalado. Parecenos que os problemas datam de muito antes da Constituição Federal de 1988.

Álvaro Lins ${ }^{6}$, já advertia desde 1946, que, no Brasil, o problema da representação era algo crônico. Os representantes do povo exerciam o poder pelo poder, sem qualquer espécie de vinculação com interesse público, ao passo que para eventual oposição restaria tão somente a possibilidade de aderir ou revolução.

É cada vez mais complexa a definição de interesse público, especialmente em um sistema normativo em que as diversas minorias coexistentes parecem ter acesso aos órgãos democráticos de produção das leis, relativizando a heteronomia normativa que, cada vez mais, apresenta-se flexibilizada. Tal fenômeno, ressalte-se, verifica-se também junto às decisões judiciais. Desse modo, a definição de interesse público é cada vez mais amplificada dada a alta complexidade de se condensar expressão cujos significados são múltiplos.

\section{1 - O interesse público primário e secundário:}

Apenas melhor definirmos o estudo a respeito das definições que cercam o interesse público, devemos aprofundar esse exame, traçando os principais aspectos relativos ao interesse público.

Como defendemos, a linha de confrontação de interesse encontra, basicamente, duas frontes. Em um dado momento existe o interesse primário, calcado no interesse geral. Este foca o seu exame no interesse social ou interesse da coletividade como um todo.

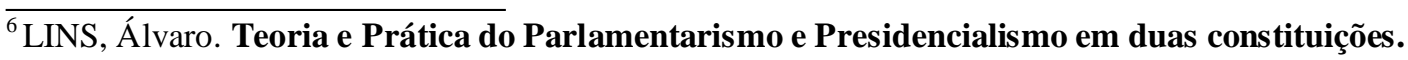


Pernambuco: editora desconhecida, 1946. P. 260. 
Quanto ao interesse secundário, este diz respeito à maneira com que a Administração entende e enxerga o interesse público, e, obviamente, tal visão se dá de acordo com os elementos que a Administração possui ${ }^{7}$.

Certamente, a grande dificuldade em se definir o interesse primário e secundário reside na característica inerente a esta definição, no caso, a definição de parâmetros que sejam confiáveis. Afinal, a toda evidência não se revela operação simples a formação de entendimento ou juízo a respeito do interesse público, que, aparentemente, se forja a partir de um cenário de conflituosidade, ou ainda, de antagonismos tais em que podemos identificar diversos interesses públicos existentes.

Aliás, neste cenário diverso, podemos visualizar, muitas vezes, inúmeras vertentes para o que vem a ser o interesse público, pelo que, identificamos, em certa medida, a sua mutabilidade, na medida em que a formação do interesse público poderá estar condicionada a questões de ordem políticas, econômicas e sociais. De qualquer forma, o condicionamento do interesse público a tais elementos se evidencia deveras perigoso e nada recomendável, eis que o poder, muitas vezes, é exercido por grupos cuja representatividade é duvidosa.

Talvez, por essa razão, a necessidade de provocarmos, em certas ocasiões, a necessária participação popular, obviamente canalizando o interesse do povo através de instrumentos de democracia direta.

\section{Juridicidade}

A filologia moderna compreende bem a expressão juridicidade. Segundo a doutrina, podemos compreender a juridicidade com sendo algo que é formado ou construído com características jurídicas ${ }^{8}$. É algo que guarda em sua formação o caráter de justiça. A juridicidade compreende, portanto, o direito justo, ou ainda, o direito legítimo.

O grande problema que apontamos ao trabalharmos com critérios abertos, como é o caso das expressões "ordem pública", "boa-fé" ou mesmo o "interesse público", é o fato de se considerar, com alguma garantia, o verdadeiro interesse público. Condensar as vontades de uma sociedade não é tarefa das mais fáceis, haja vista a multiplicação incansável de minorias, interesses e direitos que se densificam de forma célere através de microssistemas

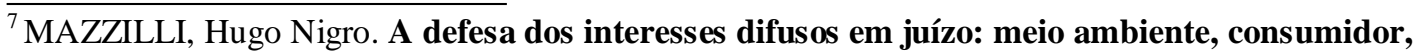
patrimônio cultural, patrimônio público e outros interesses. São Paulo:Saraiva, 2007. P.47.

${ }^{8}$ SILVA, De Plácido .Vocabulário Jurídico. Rio de Janeiro: Editora Saraiva, 2008. P. 831.
} 
jurídicos, ou ainda, corporificados através de leis e códigos que são criados com a função de traduzir interesses de apenas alguns setores sociais.

O sistema jurídico hoje vigente em nosso país, embora considerado complexo, economicamente inviável e por demais burocratizado, tem evoluído sistematicamente para um processo de simplificação, o que representa um processo sociológico desejável em qualquer democracia. Ocorre que os rumos assumidos neste processo de simplificação trazem à tona outro problema, o que NiklasLuhman costuma chamar de dupla contingência. A dupla contingência seria o processo inverso. Na verdade, dada a diversidade de sistemas hoje coexistentes, a existência de problemas chega a ser inevitável, de sorte que à solução de problemas comuns a sistemas diversos há a implicação necessária de um processo de complexização das soluções. Esse efeito reverso apontado por Luhman não é fenômeno apenas sociológico. É algo que se manifesta também no direito, como forma de legitimação de decisões judiciais entre outros interesses.

Fato é que o processo de legitimação de decisões judiciais em nosso sistema normativa apresenta processos bastante interessantes de legitimação, como, por exemplo, o processo protocolar de se construir uma decisão ${ }^{9}$. As formalidades e práticas forenses conferem legitimidade às muitas decisões prolatadas, por mais arbitrárias que sejam. É nesse ponto que reside um dos principais problemas, em nosso entendimento. A falta de comunicação, diálogo e interlocução das decisões judiciais com os jurisdicionados.

Dentre os diversos métodos de criação, desenvolvimento e formação do consenso, não há na ciência jurídica um mecanismo eficiente e capaz de permitir que os jurisdicionados participem do processo de construção de uma decisão judicial. No âmbito do processo civil, podemos apontar algumas tentativas fracassadas de se autorizar a participação de sujeitos estranhos à relação processual instaurada, destacando que, para que tal fenômeno processual seja invocado, deve ser preenchida uma série de requisitos. Portanto, a participação é limitada.

Quanto à questão do processo de legitimação de decisões, por óbvio, preferimos abordar tal questão em tomo apropriado deste pequeno ensaio, dadas as altas repercussões envolvidas para o processo de controle que nos propusemos a estudar.

De qualquer forma, mesmo apesar de a decisão judicial não contar com a justa e necessária legitimação do interesse geral, de certo sua validade será confirmada ante a existência do procedimento, regras protocolares e o fato de que a decisão judicial ou administrativa seja oriunda de uma fonte de poder: judiciário, legislativo ou executivo. 
${ }^{9}$ LUHMAN, Niklas. Legitimação pelo procedimento. Brasília: Universidade de Brasília, 1980. P.20-22. 
Mas e o que ocorre quando a decisão judicial possui critérios questionáveis de justiça? Ou seja, o que fazer quando a decisão judicial é antijurídica? Bom, primeiramente, temos que lembrar que a decisão em si não é nula. Ao contrario, é válida e capaz de produzir efeitos imediatos, não por conta de seus argumentos jurídicos ou de seu forte poder de convencimento. A decisão antijurídica somente é válida em razão de emanar de órgão de poder, como é o caso daquelas decisões oriundas do Poder Judiciário. A decisão antijurídica é consequentemente válida em razão de sua origem (fonte de poder). No entanto, sua validade é questionável, permitindo, inclusive, que outros órgão do Poder Judiciário possam declarar a antijuridicidade da decisão, seja por não corresponder ao que dizo sistema normativo, ou ainda, por não atender o interesse coletivo.

Fato é que a decisão antijurídica necessita de um processo de controle, a qual corresponde a oportunização de um diálogo entre o poder constituído e responsável pela decisão e os jurisdicionados que acatarão a decisão imposta. Controlar, em verdade, representa em nosso modelo jurídico à elaboração de um complexo sistema de comunicação entre os jurisdicionados e o poder responsável pela decisão judicial ou administrativa. A elaboração de um sistema de controle não é algo tão simples. Suas etapas passam necessariamente por diversos níveis, os quais devem ser sistematicamente testados antes da efetiva implantação.

Antes, porém, da elaboração de tal modelo, devemos examinar o processo de legitimação.

\section{A legitimação do procedimento constitucional}

Legitimar é trazer conformação generalizada a uma sociedade, ou ainda, é processo que representa a aceitação de uma decisão ou ato administrativo. A rigor, à luz de uma perspectiva constitucional, a legitimação pode também ser compreendida através do poder constituinte, ou materialmente a partir da própria constituição de um país ${ }^{10}$. De fato, é a constituição que funda o poder. É a constituição que justifica e dá legitimação. Como efeito prático deste raciocínio, a constituição ao determinar funções, órgãos, controles, limites e etc. compartilha o poder soberano que a institui, trazendo legitimação para certos atos ou condutas.

\footnotetext{
${ }^{10}$ CANOTILHO, José Joaquim Gomes. Direito constitucional e teoria da constituição. 7.ed. Coimbra: Almedina. P.1440.
} 
A legitimação das decisões judiciais representa complexo sistema de aceitação e validação do ato judicial, o qual necessariamente perpassa através da análise do direito positivo, ou ainda, o direito posto, o qual implica no reconhecimento de premissas, todas como obrigatórias, para uma determinada sociedade ${ }^{11}$.

Com efeito, podemos afirmar que hoje abandonamos quase que completamente os modelos medievais de aceitação, onde praticamente vigoravam os processos do direito natural, como única forma conhecida de legitimação. Atualmente, a sociedade é complexa e, como tal, os processos de legitimação passam, inclusive, por comportamentos e medidas protocolares para sua validação. No sistema político moderno e atual, o processo de legitimação das decisões judiciais, ao mesmo tempo em que representa o resultado prático de um complexo sistema decisório, simplifica o processo de conformação e aceitação social. As decisões judiciais traduzem, em verdade, a criação de premissas interpretativas da lei, cuja questionabilidade são deveras limitadas, após a implementação de certas condições.

Contudo, é de se ressaltar a necessidade extrema de que as decisões judiciais acompanhem o modelo estabelecido pela constituição, sob pena de serem submetidas a um rigoros sistema de controle estabelecido pela própria constituição cujo resultado último pode ser compreendido em duas dimensões: $i$ ) a confirmação da decisão judicial e a consequente legitimação da decisão; ii) o afastamento da decisão tomada e a consequente declaração de imprestabilidade da norma verificada - declaração de inconstitucionalidade.

Percebamos que a legitimação das decisões judiciais traz efeito lateral muito superior à concretização dos direitos ali concretizados, tais como: a proteção e defesa da ordem fundamental do estado, a afirmação do controle do poder político (que é o poder que elabora as leis), bem como a ordenação de um poder complexo que se presta a justificar a existência do Estado. Tais efeitos, muito embora não previstos na própria lei, são facilmente verificáveis quando examinadas as consequencias legais e políticas de qualquer decisão judicial tomada.

Aliás, a respeito desse tema, não podemos deixar de mencionar o fato de que as decisões judiciais devem sofrer uma análise consequencialista, como que uma alternativa de exame das consequencias criadas pela decisão judicial, sendo justo lembrar que devemos estudar claramente o tipo de regra de conduta que se está criando pela decisão, como essa decisão deve ser observada e etc ${ }^{12}$.

\footnotetext{
${ }^{11}$ LUHMAN, Niklas. Legitimação pelo procedimento. Brasília: Universidade de Brasília, 1980. P.32.

${ }^{12}$ LORENZETTI, Ricardo Luis. Teoria da decisão judicial: fundamentos do direito. São Paulo: Revista dos Tribunais. 2010, p. 186.
} 
A importância de um exame quanto às consequências das decisões judiciais integra o complexo sistema de legitimação, na medida em que tal exame cuida de afastar as deformações eventualmente existentes, as quais muitas vezes são inconvenientes e até superfluas para o cidadão.

O processo de legitimação passa ainda pela análise da soberania em sua dimensaõ interna, uma vez que o poder impositivo de uma decisão judicial compreende apenas uma pequena parcela do poder instituído que representa o estado ${ }^{13}$. Mais uma vez, o complexo sistema decisório existente em um país taduz a força política do poder instituído que compartilha sua soberania com os poderes existentes.

\section{O controle de juridicidade. Limites do controle}

Dentro de uma perspectiva constitucional, o controle funciona como um sistema de proteção a própria constituição. Enquanto a ordem constitucional representa as linhas gerais do Estado, estrutura, órgãos etc., estabelecem-se também, as diretrizes e os limites ao conteúdo da legislação que surge nesse contexto ${ }^{14}$. É claro e evidente que nenhum sistema de controle é eficaz o bastante a ponto de serem desconsideradas outras formas de controle e exame. Mas, sob todas as perspectivas, é fato que a constituição representa o mais importante ponto de partida.

Também não se discute o fato de que controlar é fiscalizar. Mas, para que um sistema de controle funcione de forma eficaz e atinja seus resultados, sua regulação deve se dar através de normas jurídicas específicas de organização, com a separação de papeis socialmente institucionalizada, como uma forma especial de ação ${ }^{15}$.

Em nosso sistema normativo, contemplamos, com certa amplitude, o controle que se dá através da análise legal e valorativa de constitucionalidade. Jorge Miranda defende que o exame de constitucionalidade designa conceitos de relação, ou seja, a relação que se estabelece entre uma dada constituição e uma outra lei qualquer ou um comportamento considerado $^{16}$.

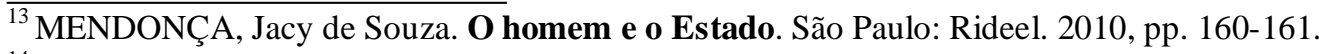

${ }^{14}$ MENDES, Gilmar Ferreira; COELHO, Inocêncio Mártires e BRANCO, Paulo Gustavo Gonet. Curso de direito constitucional. São Paulo: Saraiva. 2010, pp. 1154-1155.

${ }^{15}$ LUHMAN, Niklas. Legitimação pelo procedimento. Brasília: Universidade de Brasília, 1980. P.101.

${ }^{16}$ MIRANDA, Jorge. Manual de direito constitucional. Coimbra: Coimbra. 1983. p. 274.
} 
O controle que propomos, in casu, cuida de exame valorativo do interesse público, o qual ainda não é adequadamente regulamentado em nosso sistema de controle de constitucionalidade. Em verdade, o interesse público constitui-se em vetor primordial de análise, o qual deve ser valorizado efetivamente. Trata-se, de exame consequencial da decisão judicial prolatada calcada não apenas nos argumentos jurídicos que embasam e fundamentam a ordem judicial, mas, também, cuida de exame calcado nos efeitos.

A relação de causa e efeito de uma decisão judicial representa exame consequencialista. A fim de se evitarem deformações no sistema, o controle de juridicidade busca criar critério valorativo, sem a pretensão de estabelecer a completude do foco de análises. Ao contrário, o critério proposto busca lançar luzes sobre o verdadeiro interesse público, afastando-se do sistema as regras criadas a partir de decisões inconvenientes, ou que apliquem o direito em direta confrontação com os interesses da sociedade, tendo como limites não apenas a ordem constitucional instituída, mas a própria coletividade.

\section{Conclusões}

A variedade de sistemas jurídicos e a altíssima complexidade que nossa sociedade tem alcançado, nos últimos tempos, têm reclamado das instituições democráticas melhor adequação dos sistemas de controle e fiscalização de decisões judiciais, buscando não apenas maior eficiência quantitativa, mas, sobretudo resultados qualitativos das decisões judiciais, que, cada vez mais, criam comportamentos sociais.

O grande desafio das decisões judiciais não é a sua imutabilidade, mas, ao contrário é a sua adequação a modelos sociais que constantemente se modificam ou renovamse em razão das alternâncias do próprio poder político. Perfectibilizar um sistema de controle que dialogue com o interesse coletivo é aproximar o poder instituído dos jurisdicionados e, por via de consequência, da própria sociedade. Decisões judiciais inconvenientes, ou que prejudiquem a existência do interesse público ou coletivo não devem prevalecer. Aparentemente, o problema goza de singeleza. Todavia, em nosso sistema normativo inexiste controle valorativo calcado exclusivamente no interesse público e coletivo.

Em razão da alta complexidade de nossa sociedade, deve-se intensificar a comunicação entre o Estado instituído e a sociedade. Um controle valorativo, inquina a necessidade de se estabelecer tal diálogo, atualmente inexistente. 
Longe de se estar criando um sistema de exame calcado na complexidade esvaziada dos sistemas processuais, que, muitas vezes, aplicam a forma pela forma, o sistema de controle de interesse público chama o jurisdicionado a participar efetivamente do controle das decisões judiciais que verdadeiramente interessam a coletividade.

Certamente que a criação de um novo critério valorativo fica a depender de um bem pensado sistema jurídico lógico, normatizado, com o estabelecimento de funções, órgãos e, principalmente mecanismos que possam facilitar a comunicação entre o cidadão e os órgãos estatais responsáveis pela criação de regras de comportamento, metanormas e demais expedientes normativos dirigidos a sociedade.

A criação de tal sistema reforça o processo de legitimação das decisões judiciais, sobre tudo àquelas medidas que reverberam seus efeitos junto aos mais complexos tecidos sociais, o que não implica dizer que o interesse público deva ser dirigido ao atendimento de todas as vontades e de todos os setores sociais. Ao contrário, a legitimação do interesse público virá reforçada através de regras de comportamentos sociais que traduzam a verdadeira existência e a manutenção da coletividade.

\section{Bibliografia}

BANDEIRA DE MELlo, Celso Antônio. Curso de Direito Administrativo. São Paulo: Malheiros, 2013, 30 Edição.

CANOTILHO, José Joaquim Gomes. Direito constitucional e teoria da constituição. 7.ed. Coimbra: Almedina.

LINS, Álvaro. Teoria e Prática do Parlamentarismo e Presidencialismo em duas constituições. Pernambuco: editora desconhecida, 1946.

LORENZETTI, Ricardo Luis. Teoria da decisão judicial: fundamentos do direito. São Paulo: Revista dos Tribunais. 2010.

LUHMAN, Niklas. Legitimação pelo procedimento. Brasília: Universidade de Brasília, 1980.

MAZZILLI, Hugo Nigro. A defesa dos interesses difusos em juízo: meio ambiente, consumidor, patrimônio cultural, patrimônio público e outros interesses. São Paulo. Saraiva, 2007.

MENDES, Gilmar Ferreira; COELHO, Inocêncio Mártires e BRANCO, Paulo Gustavo Gonet. Curso de direito constitucional. São Paulo: Saraiva. 2010.

MENDONÇA, Jacy de Souza. O homem e o Estado. São Paulo: Rideel. 2010. 
MIRANDA, Jorge. Manual de direito constitucional. Coimbra: Coimbra. 1983.

SILVA, De Plácido .Vocabulário Jurídico. Rio de Janeiro: Saraiva, 2008. 
